\title{
Night time place identity: the relationship between urban public parks setting and human leisure behaviour
}

\author{
M. R. Ngesan ${ }^{1}$, H. A. Karim² \& S. S. Zubir ${ }^{3}$ \\ ${ }^{1}$ Centre for Environment-Behaviour Studies, Faculty of Architecture, \\ Planning and Surveying, Universiti Teknologi MARA, Malaysia \\ ${ }^{2}$ Centre of Studies for Town and Regional Planning, \\ Faculty of Architecture, Planning and Surveying, \\ Universiti Teknologi MARA, Malaysia \\ ${ }^{3}$ Centre of Studies for Architecture, Faculty of Architecture, Planning and \\ Surveying, Universiti Teknologi MARA, Malaysia
}

\begin{abstract}
The public realm could appear in many ways to comprise the varied identity of place influenced by a person or object and culture or environment. The purpose of this paper is to show the leisure behaviour of the urban community in relation to the setting of the urban public park during the night time. Meanwhile, the literature reviews regarding night time social behaviour and the leisure activities of community in urban outdoor spaces are limited. An improved understanding of the relationship between community leisure and an urban public park setting could be used to influence the development of future public park design, to create night time urban outdoor environments to be more conducive for community leisure activity.
\end{abstract}

Keywords: night time leisure, public park, urban community, place identity.

\section{Introduction}

Communities living in urban areas have used the outdoor public park as a place for social and leisure activities with their families, friends and others. The park plays a vital role in the social life of urban communities. Meanwhile, the hot climate during the day due to the effect of global warming has discouraged 
human activities in urban outdoor spaces [1]. Moreover, the busy lifestyle of urbanites also affects the lack of time for leisure and recreation activities in urban outdoor spaces [2]. These constraints have changed the behavioural patterns of the urban communities where people prefer to carry out their leisure activities in the outdoor public-park after the sun has set. Yet the current planning and design of outdoor public realm is not accommodative for community night time leisure and recreation [3]. Nowadays, many nightlife activities are focused on city users and tourists such as pubs, bars, nightclubs, concerts and others that disturb urban community living in the surrounding area [4]. Besides, most of the community's activities during the night time only take place indoors - in cinemas, restaurants, shopping complexes, etc. [5]. The use of indoor rather than open and green outdoor spaces in leisure time has led to a more passive urbanite lifestyle. People neglect the fact that a physically active lifestyle with an outdoor green environment is important in terms of human physical and mental health [2]. Therefore, Cheshmehzangi [6] argues that, the public realm could show itself in many ways, and that by itself, has no definite identity. In this respect, the public realm does not have a certain identity but rather is fulfilled with several changing identities influenced by content (i.e. person or object) and context (i.e. environment or culture) where content is the inherent value [7]. At this juncture, the study on night time place identity of the urban public park in relation to human leisure behaviour seems to be warranted and in line with the Malaysian Economic Transformation Programme [8], under Entry Point Project 6 (EPP6) to ensure that every resident in Greater Kuala Lumpur/Klang Valley benefits from the public green spaces. The aim of this project is to enhance the liveability cities by creating more comfortable public spaces for urban community leisure and recreational activities. For this particular research, Shah Alam and Putrajaya have been chosen as the study areas. Shah Alam is the state capital of Selangor and situated around twenty-five kilometres west of the Malaysia's capital city, Kuala Lumpur. Since gaining independence in 1957, Shah Alam can be considered as the first planned city that has incorporated the green and community concept for urban development. Meanwhile, Putrajaya is the new federal administrative centre of Malaysia after the seat of government was shifted in 1999 from Kuala Lumpur. Situated around twenty-five kilometres south of Kuala Lumpur, Putrajaya has been shaped as Malaysia’s first Intelligent Garden City.

\section{Literature review}

\subsection{The concept of place identity}

Place identity could best be understood as that which makes a place unique. It is not just the identity of a place that is important, but also the identity that a person or group has with that place [7]. Proshansky et al. [9], define place-identity as a "pot-pourri of memories, conceptions, interpretations, ideas, and related feelings about specific physical settings, as well as types of settings". Place identity changes occur throughout a person's lifetime. It is a substructure of self- 
identity and comprises perceptions and comprehensions regarding the environment. These perceptions and conceptions can be organized into two types of clusters; the first type consists of memories, thoughts, values and settings, and the second type consists of the relationship among different settings of place [10]. Place identity theory does not provide much detail regarding the structure and process [11], but refers to "schemata" that Neisser [12] describes as perceptions and ideas concerning the physical environment. Moreover, the perspectives on place have shifted from 'physical determinism' where the environment was seen as having direct effects on behaviour [13], to the view of the people-environment relation as dynamic and interactive. Akin to this, Wicker [14] emphasizes that behaviour settings are social constructs developed over time.

\subsection{The concept of place and behaviour}

The mutual relationship between space and human can be considered as sense of place or spirituality of place. Cheshmehzangi [6] mentions that, social behaviourism of a place is either controlled by design or developed with it. Therefore, environmental perception of any place has a mutual relationship with its social behaviourism termed as 'socio-environmental values' and 'spatial inter-relations'. According to Walmsley [15], the 'environment as perceived rather than the real world which influences behaviors'. Thus, certain characteristics and urban formations are important aspects of how environment can control and/or enhance social behaviour. Hague and Jenkins [16] argues that identity of a place is a matter of socio-environmental values and spatial interrelations with which place also aims to develop as well as becoming developed itself. Therefore, it is not only the place that needs to be studied but also the human himself and how he behaves and relates to his environment.

\subsection{The concept of place and time}

Cheshmehzangi [6] elucidates that actions taking place within the environment are outcomes of the urban system, which could modify qualities and adjust inner character development and future inputs within the public place. Night time activities in a public-park are part leisure and part recreation that have become an urban trend. Hague and Jenkins [16] describes that the understanding of place requires various techniques and investigations based on three factors, namely, space, nature and time. Relph [7] explicates that place can have multiple identities to one person as well as to the whole society, therefore the possibility of having different answers and results will depend on different contexts that are associated with different times. Although the 'time' refers to the time decade [10], the place can also change over the daily time.

\subsection{The concept of social behaviour and climate}

Knez [17] argues that climate is one of the attributes that brings meaning to the place of people. This ecological variable, a physical parameter of a place, plays 
an important role in everyday life. It has impact on the individual, social life and economy. Moreover, peoples' perceptions towards the beauty of places are different due to factors of microclimatic conditions such as sunlight and wind. These and other microclimatic parameter such as temperature and humidity may also influence our perception towards comfort. According to Emmanuel [18], the Urban Heat Island (UHI) at night time in an urban centre is highly correlated with the urban tree cover characteristic. Night time cooling in an urban centre could be achieved by increasing the Sky View Factor (SVF) and improving the thermal properties. During the night time, the thermal properties such as green surface in the open area with less tree cover are more cooling due to the increase in the SVF that realizes heat from the effect of UHI.

\section{Methodology}

\subsection{The aim and case study area}

The purpose of this paper is to study night time place identity by investigating the influence of spatiality on the urban public park setting with the night time leisure activity of community. That is, they are expected to exhibit positive social behaviour and activity when the spaces of urban public parks are used at night. Shah Alam and Putrajaya have been chosen as the study areas due to their subdued urban nature - well provided community facilities; and the lack of night time commercial and entertainment centres. The strategy chosen for the research design was based on a case study [19]. All the three case study areas are located in the respective city centres. The two urban public parks are in Section 14, Shah Alam known as Padang A and Padang B; and the other one known as Padang Putrajaya in Precinct 3, Putrajaya.

\subsection{Research design}

The methodology emulated previous studies done by Zimmons [20] and Moore [21] were based on a quasi-experiment in children behaviour at outdoor spaces in one area, while the present study is based on community night time leisure behaviour involving adults, teenagers and children in three areas of urban public park. This study will use a place-centred mapping survey as part of behavioural mapping technique to observe how people use the space [22]. Data collected based on this methodology involved personal observation, video recording and behavioural mapping. The observation survey involved natural unobtrusive observation and video recording of group behaviour at urban park during the night time. The behavioural mapping involved charting community behaviour and activity at pre-drawn. The behavioural mappings have to be included in order to identify the spatial choice and location in the urban park [23].

\subsection{Procedure}

The time sampling is taken for 10 minutes with a time interval of 20 minutes for each study area [24]. Earlier observations have been undertaken to verify the 
observation form as a checklist for the main survey and to determine the higher use of the urban park at night as a time-frame survey [25]. It was found that the urban park begins to be crowded in the night during weekends, starting from 8.00pm until 12 midnight. The enumerators arrived 30 minutes before the observation period to ensure that ample time was available for setting up the video camera etc. In total, there were 27 maps collected during the observation sessions for the three case study areas. Each area collected nine maps, which is ten minutes per map. The researcher also used some variables in the System for Observing Play and Active Recreation in Communities (SOPARC) as part of the component in the analysis stage. SOPARC was designed to obtain direct information on community park use, including their users [26].

\section{Findings and discussion}

The survey illustrates that the average users of an urban park during the night time at the three case study areas during the observation days were 382 people. This supports an argument by Alves [27] and Ngesan et al. [28], that night-time leisure activity has become an urban trend. Givoni [29] states that, success in fulfilling the social functions of an urban public park may be measured by the frequency of visitation by the community which depends upon the existence of proper conditions. The user in the case study area of Padang A in Shah Alam (279 people) is higher compared to the Padang B (70 people) even though the area of Padang A (1.79 hectare) is smaller than Padang B (2.52 hectare). This has a relation with the location of the study area where Padang A is located in the middle of iconic buildings such as Shah Alam Gallery, Auditorium, Blue Wave Hotel, Blue Mosque Shah Alam and many others, which give an interesting lighting silhouette at night rather than Padang B which is located beside a main road junction. Moreover, the differences of ground cover characteristic and condition in the study area that affect the Urban Heat Island, where Padang A is covered fully by grass and Padang B is covered with a mixture of grass and sand surface has influenced the site preferences for leisure at night. Meanwhile, Ngesan et al. [3] postulates that the crowd in the urban public park during the night time would decrease the user's perception from the aspects of comfort, convenience and safety of the place while carrying out night time leisure activities.

The findings also reveal that the urban public park of Padang Putrajaya (1.0 hectare) perceived the lowest average users (32 people) at night compared to Padang A and Padang B in Shah Alam. Although Padang Putrajaya has a quite similar physical character with Padang A in Shah Alam and adapted the same development concept of garden city, the result has indicated a different number of visitation frequencies. Since Shah Alam started earlier in 1957 than Putrajaya in 1999, the land use development and urban public parks have evolved with time and socio-culture of the local urban community. Moreover, the rapid development of land use and buildings activities in the neighbouring Shah Alam and surrounding area of urban public parks also contributes to the vibrancy and vitality of night time leisure behaviour in the urban public parks of Shah Alam. 
Therefore, the Padang Putrajaya is not only used for community leisure but is also used as a place for federal ceremony/events to improve the function of the area. Since the influence of the physical environment, climate and time on human behaviour has been well documented in the literature review, this paper posits that the exhibition of more appropriate behaviours by people during the night time was the outcome of better outdoor space design. The results from the behavioural mapping survey data are shown in tables and diagrams based on the sub topics namely; 1 . The use of the urban park at night by gender and age group such as children, teenagers, and adults; 2 . The positions in the urban park during the night time, namely, sitting on a bench, sitting on the grass, standing and lying on the grass; and 3. The types of physical activity levels in urban park during the night time like sedentary, moderate, and vigorous. At the end of the discussion, the diagram of physical activity mapping of night time leisure will show the distribution of activity in the study area.

\subsection{The use of the urban park at night time by age group and gender}

The highest numbers of percentage in the age groups are adults totalling 69.32 percent (see Table 1). The findings reveal that although the adults have to work during the day, these age groups of people are able to spend time in leisure activities with their friends and families in public outdoor spaces at night time. Moreover, the slightly different percentage of gender between males (52.09 percent) and females (47.91 percent) highlight the existence of families and group of friends (see Table 2). It supports the findings from the observation survey that the majority of users are the groups of family and friends. The existence groups of women indicate that community perceived urban park as a safe place at night time [30]. Hence, the existence of children, which is 26.2 percent, shows that the place is safe. According to Ozcan [31], children are known to be more

Table 1: $\quad$ The use of the urban park at night time by age group.

\begin{tabular}{|l|l|l|l|}
\hline Location & Children & Teenagers & Adults \\
\hline Padang A Shah Alam & 20.32 & 2.97 & 49.84 \\
\hline Padang B Shah Alam & 4.48 & 0.64 & 13.25 \\
\hline Padang Putrajaya & 1.40 & 0.87 & 6.23 \\
\hline Total & 26.2 & 4.48 & 69.32 \\
\hline
\end{tabular}

Table 2: $\quad$ The use of the urban park at night time by gender.

\begin{tabular}{|l|l|l|}
\hline Location & Male & Female \\
\hline Padang A Shah Alam & 37.82 & 35.31 \\
\hline Padang B Shah Alam & 9.64 & 8.73 \\
\hline Padang Putrajaya & 4.63 & 3.87 \\
\hline Total & 52.09 & 47.91 \\
\hline
\end{tabular}


sensitive in their perception of the physical environment; hence it has a greater effect on the way they conduct themselves. Besides that, teenagers, comprising 4.48 percent also reveal that, night time activities in urban parks are attractive to this age group. This can reduce unwarranted juvenile activities. Thus, the park users comprised all age groups and a balanced number of gender. These illustrate varieties of users in the urban park at night time which forms cordial community social relationships in the urban area.

\subsection{The users' leisure position in the urban park at night time}

Table 3 shows Padang A in Shah Alam as having a higher percentage in all the positions' behaviour in the urban park. This position is influenced by the ground cover characteristic, which is grass. As mentioned earlier, Padang A is fully covered by grass and Padang B is covered with mixed grass and sand (see Figure 1). Although the character of surrounding area and the ground cover of Padang Putrajaya is quite similar to Padang A in Shah Alam, the condition of the grass is not very fertile due to the trace of events' canopies and equipment after a federal ceremony. Since the physical character place of study areas are without any playground facilities, the users prefer to use the ground surface as the place for their activities. Moreover, the position behaviour of sitting on grass is higher compared to the sitting on benches in the case study of Shah Alam's Padang A and Padang B than Padang Putrajaya. These findings support the argument by Ngesan and Karim [32] that the ground surface materials and condition for night time leisure activity in an urban public park are able to influence the users' position behaviour. The position of lying on the grass, comprising 2.42 percent, also shows that the minimum light pollution during the night time in the study area due to the clear visibility of the moon and stars [33]; can be enjoyed by urbanites in Shah Alam.

Table 3: $\quad$ The percentage of users' leisure position in an urban park at night time.

\begin{tabular}{|l|l|l|l|l|}
\hline Location & Sitting on bench & Sitting on grass & Standing & Lying on grass \\
\hline Padang A Shah Alam & 9.75 & 19.88 & 42.97 & 0.53 \\
\hline Padang B Shah Alam & 4.72 & 5.62 & 7.74 & 0.29 \\
\hline Padang Putrajaya & 3.11 & 0.96 & 4.37 & 0.06 \\
\hline Total & 17.58 & 26.46 & 55.08 & 0.88 \\
\hline
\end{tabular}

\subsection{Physical activity in an urban park at night time}

The analyses of physical activity are based on variables in the SOPARC. There are three physical activity levels, namely, sedentary, moderate and vigorous. Sedentary refers to the behaviour of lying, sitting or standing. Moderate refers to recreation and fitness, while vigorous refers to activities that increase human heart rate, causing them to sweat. Based on an earlier observation survey, the night time leisure activities have been listed and categorized into the three levels. Table 4 illustrates that the highest level activity is sedentary at 61.09 percent, 
while the highest of the total types of physical activity is talking/socializing at 23.00 percent. Night time leisure also involved physical activity from a moderate level (24.47 percent) and a vigorous level (14.44 percent). The variation of physical activity level is due to the existence of multiple night time users in an urban public park such as family with children; and groups of friends from different age groups and genders. Zaki and Ngesan [34] argued that the agglomeration of night time activity is able to create different activity to attract people. Meanwhile, night time leisure activities should have time limitations to ensure the normal circadian rhythm cycle for a living being that requires the human body to sleep and rest at night [35].

Table 4: $\quad$ The physical activity in an urban park at night time.

\begin{tabular}{|c|c|c|c|c|c|c|}
\hline 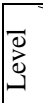 & 4.4ypes $\quad$ Location & $\begin{array}{l}\text { Padang A } \\
\text { Shah Alam }\end{array}$ & $\begin{array}{l}\text { Padang B } \\
\text { Shah Alam }\end{array}$ & $\begin{array}{l}\text { Padang } \\
\text { Putrajaya }\end{array}$ & $\begin{array}{l}\text { Total } \\
\text { types of } \\
\text { activity }\end{array}$ & $\begin{array}{l}\text { Total } \\
\text { levels of } \\
\text { activity }\end{array}$ \\
\hline \multirow{4}{*}{ 忞 } & Quiet relaxation/reading & 13.89 & 2.53 & 1.72 & 18.14 & \multirow[t]{4}{*}{61.09} \\
\hline & Talking/socializing & 15.75 & 5.01 & 2.24 & 23.00 & \\
\hline & Uses electronic devise & 1.92 & 0.82 & 0.71 & 3.45 & \\
\hline & Eating/picnicking/party & 11.03 & 3.87 & 1.60 & 16.50 & \\
\hline \multirow{2}{*}{ 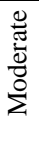 } & 4.4.1.1.1.1.1 & 6.78 & 1.31 & 0.35 & 8.44 & \multirow[t]{2}{*}{24.47} \\
\hline & $\begin{array}{l}\text { Playing: bubble } \\
\text { game/lighting game etc. }\end{array}$ & 13.94 & 1.60 & 0.49 & 16.03 & \\
\hline \multirow[t]{2}{*}{ 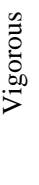 } & 4.4.1.1.1.1.1.1 & 2.91 & 1.16 & 0.61 & 4.68 & \multirow[t]{2}{*}{14.44} \\
\hline & $\begin{array}{l}\text { Sports: football, badminton, } \\
\text { boomerang etc. }\end{array}$ & 6.90 & 2.07 & 0.79 & 9.76 & \\
\hline
\end{tabular}

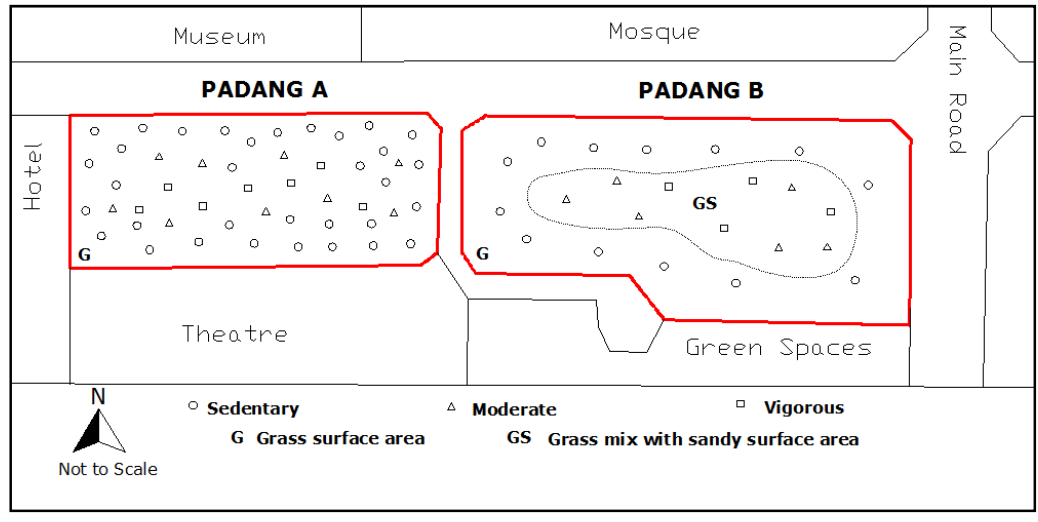

Figure 1: Physical activity behaviour map in Padang A and Padang B, Shah Alam. 


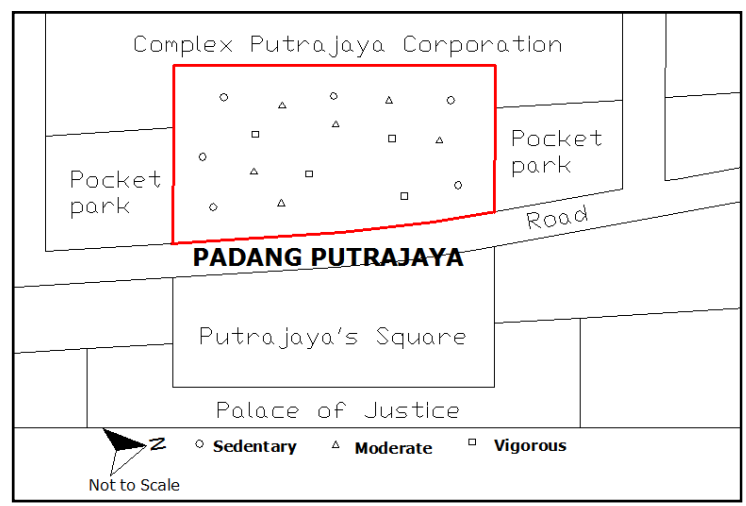

Figure 2: $\quad$ Physical activity behaviour map in Padang Putrajaya.

Figures 1 and 2 show the distribution of physical activities in the case study of an urban park during the night time. The sedentary activities in Padang A, Shah Alam are scattered in all areas, while in Padang B and Padang Putrajaya are located at the edges of the area. The moderate activities in the three case studies are identified to be located close to sedentary activity. Vigorous activity tends to be scattered in Padang A and located in the centre of the area in Padang B and Padang Putrajaya. Moreover, Padang A is more condensate compared to Padang B and Padang Putrajaya due to the different ground cover material and condition; and building activity in the surrounding area of Padang. Besides, Padang A is also lit up compared to Padang B and Padang Putrajaya since the light is a factor that contributes towards the sense of safety and security of the place [36].

\section{Conclusion and recommendations}

This research found that the urban community used outdoor public spaces for night time leisure activities. The findings showed that the night time users were ranging different ages, genders and groups of the urban community. This indicates that the urban public park which is efficiently designed to meet urban liveability could encourage the social relations among the community to achieve the highest quality of urban life. The elements of lighting, ground material characteristic, park facilities and the surrounding building uses activities contribute to the preferences of place for night time leisure in outdoor spaces. This reveals how human behaviour responds to the physical setting of an urban public park at different times of night dimension. Moreover, the evolutions of time with the place and the rapid development of the neighbouring city influence the vitality of the night time urban public park. Such evidence may contribute to new knowledge in the environmental behaviour studies, urban design and landscape; that can help to improve the design of public outdoor spaces to create bonds of identity between people and places. These findings may also be used to improve the guidelines and policies regarding future urban public park 
development. As this study is confined to the case study of the urban public park in Shah Alam and Putrajaya, it is suggested that future research should involve more samples of urban parks nationwide. The slight differences in the behavioural patterns observed with regards to physical activity within the confinement of the different urban park settings should also be noted. As the analysis of this phenomenon is beyond the scope of this paper, it could be investigated further in future studies.

\section{Acknowledgements}

The authors would like to acknowledge Universiti Teknologi MARA (UiTM), Shah Alam City Council (MBSA) and Putrajaya Corporation (PPJ) for their endless assistance given during the course of carrying out the study. This study was funded by Research Intensive Faculty (Grant 600-RMI/DANA 5/3/RIF 264/2012), provided by Research Management Institute (RMI), Universiti Teknologi MARA Shah Alam, Malaysia.

\section{References}

[1] Ewert, A.W., Outdoor recreation and global climate change: Resource management implications for behaviours, planning, and management. Society and Natural Resouces, 4, pp. 365-377, 1991.

[2] Oguz, D. and Cakci, I., Changes in leisure and recreational prefrences: A case study of ankara. Scientific Research and Esseys, 5(8), pp. 721-729, 2010.

[3] Ngesan, M.R., Karim, H.A. and Zubir, S.S., Urban community perception on night time leisure activities in improving public park design. Papers proceeding. Asia Pacific International Conference on EnvironmentBehaviour Studies 2013 London, 2013.

[4] Ngesan, M.R. and Karim, H.A., Impact of night commercial activities towards quality of life of urban residents. Procedia - Social and Behavioral Sciences, 35, pp. 546-555, 2011.

[5] Erkip, F., The shopping mall as an emergent public space in Turkey. Environment and Planning, 35, pp. 1073-1093, 2003.

[6] Cheshmehzangi, A., Identity and public realm. Procedia Social and Behavioural Sciences, 50, pp. 307-317, 2012.

[7] Relph, E., Place and placelessness, London: Pion Limited, 1976.

[8] Economic Transformation Programme. A roadmap for Malaysia. Chapter 5: Greater Kuala Lumpur/Klang Valley. Performance Management and Delivery Unit, 2010.

[9] Proshansky, H.M., Fabian, A.K., and Kaminoff, R., Place-identity: Physical world socialization of the self. Journal of Environmental Psychology, 3, pp. 57-83, 1983.

[10] Proshansky, H.M., and Fabian, A.K., The quality of urban life. Walter de Gruyter \& Co. New York, 1987. 
[11] Twigger-Ross, C.L., Bonaiuto, M., and Breakwell, G., Identity theories and environmental psychology. Aldershot, England: Ashgate, 2003.

[12] Neisser, U., Cognition and Reality. San Francisco: Freeman, 1976.

[13] Franck, K., Exorcising the ghost of physical determinism. Environment and Behavior, 16(4), pp. 411-435, 1984.

[14] Wicker, A.W., An introduction to ecological psychology. Monterey, CA: Brooks/Cole, 1979.

[15] Walmsley, D. J., Urban living: The individual in the city, Harlow: Longman Scientific and Technical, 1988.

[16] Hague, C. and Jenkins, P., Place identity, planning and participation, London: Routledge, 2005.

[17] Knez, I., Attachment and identity as related to a place and its perceived climate. Journal of environmental psychology, 25, pp. 207-218, 2005.

[18] Emmanuel, M.R., An urban approach to climate sensitive design Strategies for the tropics. Spon Press Taylor \& Francis Group, 2005.

[19] Yin, Y.K., Case study research - Design and methods (2nd ed.). London: Sage Publications, 1994.

[20] Zimmons, J.K., The effect of spatial definition on preschool prosocial interaction. Doctoral dissertation, Texas Tech University, USA, 1997.

[21] Moore, G.T., The Children's Physical Environments Rating Scale (CPERS). Sydney: Environment, Behaviour and Society Research Group, University of Sydney, Australia, 2008.

[22] Creswell, J. W., Research design, Second Edition. Thousand Oaks: Sage Publications, 2002.

[23] Morrow, V., Using qualitative methods to elicit young people's perspectives on their environments: Some ideas for community health initiatives. Health Education Research, 16, pp. 255-268, 2001.

[24] Abbas, M.Y. and Othman, M., Social behaviour of preschool children in relation to physical spatial definition. Procedia Social and Behavioural Sciences, 5, pp. 935-941, 2010.

[25] Marcus, C. C., From the pragmatic to the spiritual. In I. Altman and K. Christensen (Eds.), Environment and behavior studies: Emergence of intellectual traditions (pp. 111-140). New York: Plenum Press, 1990.

[26] McKenzie, T. L., Cohen, D. A., Sehgal, A., Williamson, S., and Golinelli, D., System for Observing Play and Leisure Activity in Communities (SOPARC): Reliability and feasibility measures. Journal of Physical Activity and Health, 1, pp. 203-217, 2006.

[27] Alves, T., A noite, a cidade e a geografia das actividades económicas, Geophilia. O sentir e os sentidos da Geografia. Homenagem a Jorge Gaspar, ed. Centro de Estudos Geográficos, Lisboa, pp. 498-500, 2007.

[28] Ngesan, M.R., Karim, H.A. and Zubir, S.S., Human behaviour and activities in relation to Shah Alam urban park during night time. ProcediaSocial and Behavioural Sciences, 68, pp. 427-238, 2012.

[29] Givoni, B., Climate consideration in building and urban design. John Wiley \& Son. Inc, 1998. 
[30] Mitchell, D., The end of public space? People's park, definitions of the public, and democracy. Annals of the Association of American Geographers, 85(1), pp. 108-133, 1995.

[31] Ozcan, H., Healing design: A holistic approach to social interaction in pediatric intensive care units in the United States and Turkey, $\mathrm{PhD}$ Dissertation,Texas A \& M University, USA, 2006.

[32] Ngesan, M.R. and Karim, H.A., Night time social behavior in urban outdoor spaces of Shah Alam. Procedia-Social and Behavioural Sciences, 50, pp. 959-968, 2012.

[33] Starlight Initiative, Light pollution: Intelligent lighting, 2007. Online. http.://www.starlight2007.net/lightpoll ution.htm.

[34] Zaki, S.A and Ngesan, M.R., Concept of night city: A new dimension to a city's economy. Asian Journal of Environment-Behaviour Studies, 3, pp. 26-34, 2012.

[35] Kolmos, E. and Davis, S.J., Circadian rhythms: Rho-related signals in time-specific light perception. Current Biology, 17(18), pp. 808-810, 2007.

[36] Hennessy, G., Seize the night: The business and culture of new york nightlife. CreateSpace Independent Publishing Platform, 2010. 